CASE REPORT

\title{
Statin precipitated lactic acidosis?
}

\author{
R Neale, T M Reynolds, W Saweirs
}

J Clin Pathol 2004;57:989-990. doi: 10.1136/icp.2004.015958

An 82 year old woman was admitted with worsening dyspnoea. Arterial blood gases were taken on air and revealed a $\mathrm{pH}$ of 7.39 , with a partial pressure of $\mathrm{CO}_{2}$ $\left(\mathrm{pCO}_{2}\right)$ of $1.2 \mathrm{kPa}, \mathrm{pO}_{2}$ of $19.3 \mathrm{kPa}, \mathrm{HCO}_{3}$ of $13.8 \mathrm{mmol} /$ litre, and base excess of $-16.3 \mathrm{mmol} /$ litre: a compensated metabolic acidosis with hyperventilation induced hypocapnia, which is known to be a feature of lactic acidosis. There was also an increased anion gap ((Nal $40+\mathrm{K} 4.0)-(\mathrm{Cl} 106$ $+\mathrm{HCO}_{3}$ 13.8) = $24.2 \mathrm{mEq} /$ litre (reference range, 7-16)), consistent with unmeasured cation. Lactate was measured and found to be raised at $3.33 \mathrm{mmol} /$ litre (reference range, 0.9-1.7). After exclusion of common causes of lactic acidosis Atorvastatin was stopped and her acid-base balance returned to normal. Subsequently, thiamine was also shown to be deficient. The acidosis was thought to have been the result of a mitochondrial defect caused by a deficiency of two cofactors, namely: ubiquinone (as a result of inhibition by statin) and thiamine (as a result of dietary deficiency).

A n 82 year old woman was admitted after six weeks of worsening dyspnoea. She was breathless at rest and unable to carry out her normal daily activities. She reported no fever, cough, chest pain, or orthopnoea. She had a history of chronic obstructive pulmonary disease, mild hypertension, and had suffered a deep vein thrombosis 12 months previously. Drug regimen on admission was Beclomethosone inhaler, $200 \mu \mathrm{g}$ twice daily (bd); salbutamol inhaler, $200 \mu \mathrm{g}$ four times daily (qds); salmeterol inhaler, $200 \mu \mathrm{g}$ qds; prednisolone e/c, 5 mg once daily (od); ciprofloxacin, $500 \mathrm{mg}$ bd (started two days before admission); lansoprazole, $15 \mathrm{mg}$ od; fluoxetine, $20 \mathrm{mg}$ od; coamilofruse, 2.5/20 od; calcichew, D3 forte od; paracetamol, $1 \mathrm{~g}$ qds; and glycerol trinitrate spray as required. Atorvastatin was noted to be part of her medication 18 months previously on her first admission to Queen's Hospital via casualty. It is presumed that it was started in the community because of her congestive heart disease and angina, but no reason for prescription was ever identified. The lipid profile on admission was total cholesterol, $5.3 \mathrm{mmol} /$ litre; high density lipoprotein cholesterol, $2.1 \mathrm{mmol} /$ litre; calculated low density lipoprotein cholesterol, $2.5 \mathrm{mmol} / \mathrm{litre}$; and triglycerides, $1.6 \mathrm{mmol} /$ litre.

Examination revealed a respiratory rate of 30 and decreased breath sounds bilaterally, with a few crepitations on chest auscultation. She was apyrexial and the rest of the examination was unremarkable. She had a normal white blood cell count and no other inflammatory markers were assessed. Chest radiograph showed no focal abnormality. The patient was started on antibiotics and nebulised bronchodilators for a possible chest infection. A computed tomography pulmonary angiogram was normal and an echocardiogram was unremarkable.

Arterial blood gases (ABGs) were taken on air and revealed a $\mathrm{pH}$ of 7.39 , with a partial pressure of $\mathrm{CO}_{2}\left(\mathrm{pCO}_{2}\right)$ of $1.2 \mathrm{kPa}$,
$\mathrm{pO}_{2}$ of $19.3 \mathrm{kPa}, \mathrm{HCO}_{3}$ of $13.8 \mathrm{mmol} / \mathrm{litre}$, and base excess of $-16.3 \mathrm{mmol} /$ litre: a compensated metabolic acidosis with hyperventilation induced hypocapnia, which is known to be a feature of lactic acidosis. There was also an increased anion gap $\left((\mathrm{Nal} 40+\mathrm{K} 4.0)-\left(\mathrm{Cl} 106+\mathrm{HCO}_{3} 13.8\right)=24.2 \mathrm{mEq} /\right.$ litre (reference range, 7-16)), consistent with unmeasured cation (lactate). This was thought probably to be contributing to her dyspnoea and a cause was sought. She was on no medications that are known to cause a metabolic acidosis and was not known to be diabetic, with normal blood glucose readings. Her renal function was good (admission creatinine, $118 \mu \mathrm{mol} /$ litre (reference range, 50-110)), but her estimated glomerular filtration rate was decreased at $26.6 \mathrm{ml} / \mathrm{minute}$ (calculated by Cockcroft and Gault equation) and her liver function tests showed no rises in transaminases or bilirubin. Lactate was measured and found to be raised at $3.33 \mathrm{mmol} /$ litre (reference range, 0.9-1.7). The patient was not hypoxic because her ABGs on air showed acceptable $\mathrm{pO}_{2}$ and she was not clinically septic. Furthermore, she was not diabetic and was therefore not on oral hypoglycaemic agents, which have been associated with lactic acidosis (especially biguanidesphenformin-which is now withdrawn from use). ${ }^{1}$ A more obscure cause for her lactic acidosis was looked for.

Normal sodium and potassium values on admission $(\mathrm{Na}$, $139 \mathrm{mmol} / \mathrm{litre}$ K, $4.0 \mathrm{mmol} / \mathrm{litre}$ ) were thought to exclude a renin-aldosterone axis cause (specifically hypoaldosteronism). Renin (4.1 nmol/litre/h (reference range, 0.76-3.2 erect)) and aldosterone (1041 pmol/litre (reference range, 110-860 erect)) were mildly raised, but these values were felt to be consistent with her diuretic treatment. Vitamin D (25$\mathrm{OH}$ cholecalciferol) was normal: $24.5 \mu \mathrm{g} /$ litre (reference range, 5-30), and no paraprotein was demonstrable on serum electrophoresis. Similarly, leukaemia and reticulosis were demonstrably absent on a full blood count.

The only likely remaining causes were a metabolic myopathy and thiamine deficiency. It is well known that statins can cause myopathy and rhabdomyolysis. ${ }^{2}$ The patient was taking Atorvastatin at $10 \mathrm{mg} /$ day. This was stopped and she immediately improved clinically. Her ABGs and lactate values repeated one week later revealed $\mathrm{pH} 7.44, \mathrm{pCO}_{2}$ of $3.9 \mathrm{kPa}, \mathrm{pO}_{2}$ of $10.8 \mathrm{kPa}, \mathrm{HCO}_{3}$ of $22.3 \mathrm{mmol} /$ litre, and base excess of $-3.9 \mathrm{mmol} /$ litre. Her lactate had returned to normal at $1.71 \mathrm{mmol} /$ litre. Her dyspnoea was also moderately improved. Therefore, it was possible that the lactic acidosis was related to the statin treatment. Six weeks later, the results of red cell transketolase enzyme activity became available: transketolase $0.65 \mathrm{U} / \mathrm{g}$ haemoglobin (reference range, $0.42-1.12$ ), with a $>50 \%$ increase in activity when thiamine was added to the assay reagent (reference, $<25 \%$ ), indicating frank thiamine deficiency. She was therefore started on thiamine treatment at this time.

Abbreviations: $A B G s$, arterial blood gases; bd, twice daily; $\operatorname{coQ}_{10}$, coenzyme $Q_{10} ; H M G C o A$, hydroxymethylglutaryl $\operatorname{CoA}$; od, once daily; qds, four times daily; $P$, partial pressure 


\section{DISCUSSION}

We have reported an unusual case of lactic acidosis that appeared to resolve as a result of cessation of statin treatment. Possible causes for lactic acidosis included thiamine deficiency, vitamin D deficiency, myeloma, or abnormal renin-aldosterone functioning. ${ }^{3}$ It was later found that thiamine deficiency was also present and this may have acted in tandem with the statin to cause lactic acidosis, when neither element individually would have been sufficient.

Statins work by inhibiting hydroxymethylglutaryl-CoA (HMGCoA) reductase, but in addition to reducing cholesterol synthesis there is a decrease in the production of other nonsterols, such as coenzyme $\mathrm{Q}_{10}$ ( $\mathrm{CoQ}_{10}$; ubiquinone), ${ }^{4}$ and HMGCoA reductase inhibitors have been shown to reduce $\mathrm{CoQ}_{10}$ concentrations. ${ }^{5} \mathrm{CoQ}_{10}$ is an essential carrier in the mitochondrial respiratory chain that participates in oxidative phosphorylation. Consequently, there is decreased activity of mitochondrial complex 1 with inadequate substrate (acetylCoA and $\alpha$-ketoglutarate tricarboxylic acid cycle effect) and reduced electron carrier transport ( $\mathrm{CoQ}_{10}$ effect). One other possible case has been reported, ${ }^{4}$ although that patient also had signs of hepatitis, which was not present in our patient.

"Thiamine deficiency was also present and this may have acted in tandem with the statin to cause lactic acidosis, when neither element individually would have been sufficient $^{\prime \prime}$

Some weeks after the resolution of our patient's acidosis, an alternative cause (thiamine deficiency) was identified and treated. Thiamine diphosphate is the active form of thiamine, and it serves as a cofactor for several enzymes, both cytosolic and mitochondrial. Isolated mitochondria have been shown to take up thiamine, yet thiamine diphosphokinase is cytosolic and not present in mitochondria. There are several thiamine transporters, and the intracellular expression of these molecules is unclear, but at least one is found in mitochondria and/or peroxisomes. ${ }^{6}$ Thiamine diphosphate serves as a cofactor for several enzymes that are found both in the cytosol (transketolase) and mitochondria (the $\alpha$-ketoglutarate dehydrogenase complex is the best studied example).

Finally, there are several other possible causes that could be considered. Non-steroidal anti-inflammatory drugs can cause uncoupling of oxidative phosphorylation, ${ }^{7}$ but our patient was not taking these; ethanol abuse can interfere with mitochondrial DNA synthesis, ${ }^{7}$ but there was no history of alcohol abuse; heterozygous McArdle's disease (myophosphorylase deficiency) may have contributed because it can cause hyperlactataemia, ${ }^{8}$ but the forearm exercise test is for homozygous disease and we did not have access to a DNA test for the heterozygote status.
Take home messages

- We report an unusual case of lactic acidosis thought to be caused by a mitochondrial defect resulting from a deficiency of two cofactors: ubiquinone and thiamine

- The deficiency in ubiquinone was a result of inhibition by treatment with Atorvastatin and the thiamine deficiency was dietary in origin

- When treatment with Atorvastatin was stopped the patient's acid-base balance returned to normal

Thus, both statin treatment, via decreased $\operatorname{coQ}_{10}$, and thiamine deficiency, via reduced $\alpha$-ketoglutarate dehydrogenase complex activity, can result in impairment of mitochondrial oxidative phosphorylation. It is possible that the lactic acidosis was the result of the combination of both thiamine deficiency and statin treatment, such that removal of one element was sufficient to resolve the metabolic stress and result in the resolution of acidosis.

\section{Authors' affiliations}

R Neale, W Saweirs, Queen's Hospital, Belvedere Road, Burton-on-

Trent, Staffordshire, DE13 ORB, UK

T M Reynolds, Queen's Hospital, Burton-on-Trent and Division of Clinical Sciences, Wolverhampton University, Wolverhampton, UK

Correspondence to: Professor T M Reynolds, Clinical Chemistry Department, Queen's Hospital, Belvedere Road, Burton-on-Trent Staffordshire, DE13 ORB, UK; tim.reynolds@ burtonh-tr.wmids.nhs.uk

Accepted for publication 20 April 2004

\section{REFERENCES}

1 Gan SC, Barr J, Arieff Al, et al. Biguanide-associated lactic acidosis. Case report and review of the literature. Arch Int Med 1992;152:2333-6.

2 Bolego C, Baetta R, Bellosta S, et al. Safety considerations for statins. Curr Opin Lipidol 2002;13:637-44.

3 Cohen RD, Woods HF. Disturbances of acid-base homeostasis. In: Weatherall DJ, Ledingham JGG, Warrell DA, eds. Oxford textbook of medicine, 2nd ed. Oxford: Oxford University Press, 1989:9.164-9.175.

4 Goli AK, Goli SA, Byrd RP Jr, et al. Simvastatin-induced lactic acidosis: a rare adverse reaction? Clin Pharmacol Ther 2002;72:461-4.

5 De Pinieux G, Chariot P, Ammi-Said M, et al. Lipid-lowering drugs and mitochondrial function: effects of HMG-CoA reductase inhibitors on serum ubiquinone and blood lactate/pyruvate ratio. Br J Clin Pharmacol 1996:42:333-7.

6 Song Q, Singleton CK. Mitochondria from cultured cells derived from normal and thiamine-responsive megaloblastic anemia individuals efficiently import thiamine diphosphate. BMC Biochem 2002;3:8 (http:// www.biomedcentral.com/1471-2091/3/8)

7 Fosslien C. Mitochondrial medicine-molecular pathology of defective oxidative phosphorylation. Ann Clin Lab Sci 2001;31:25-67.

8 Kazemi-Esfarjani P, Skomorowska E, Jensen TD, et al. A nonischemic forearm exercise test for McArdle disease. Ann Neurol 2002;52:153-9. 